\title{
Concepção de Família por Parte de Crianças em Situação de Acolhimento Institucional e por Parte de Profissionais
}

\section{Concept Of Family By Children At Residencial Care And By Professionals}

Concepción De Familia Por Parte De Niños En Situación De Acogimiento Institucional Y Por Parte De Profesionales
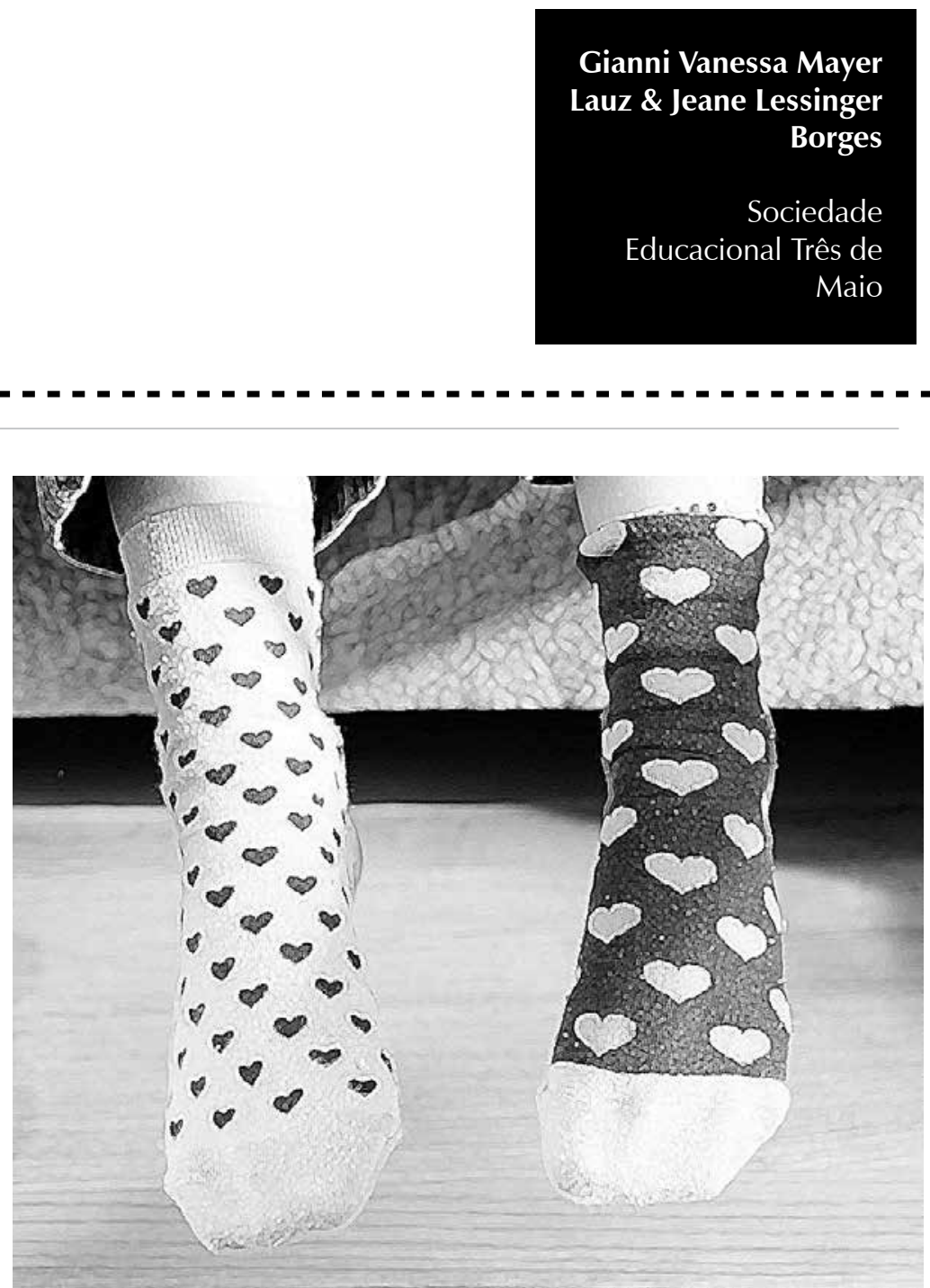
Resumo: Este estudo objetivou conhecer a concepção de família para crianças em situação de acolhimento institucional bem como para profissionais da mesma instituição. Participaram do estudo três meninas, entre nove e dez anos de idade, e três profissionais (uma assistente social, uma monitora e a diretora). A coleta de dados com as crianças foi realizada através de um grupo focal (GF), em que foram utilizados recursos lúdicos e simbólicos. Além disso, foi solicitado o desenho da família e realizada uma entrevista semiestruturada individual. Já com os profissionais, fez-se o uso de entrevistas semiestruturadas. Os resultados foram analisados através da análise de conteúdo, e os dados encontrados apontaram que as crianças possuem a representação de família relacionada à família de origem, à família monoparental e à família nuclear. A percepção dos profissionais é formada pelas representações de suas famílias de origem e pela percepção das famílias das crianças institucionalizadas sob o viés dos riscos e da culpabilização. Assim, torna-se necessário abrir espaços para reflexões sobre o modelo de família junto à equipe da instituição, a fim de que possam notar as novas configurações familiares na sociedade atual e os fatores de proteção presentes nas famílias de origem das crianças, superando uma visão patologizante.

Palavras-chave: Família. Criança institucionalizada. Fatores de risco. Estrutura familiar. Abrigos.

Abstract: This work investigated the concept of family to children in residential care, as well as to professionals from the same institution. Three girls between nine and ten years old and three professionals (a social worker, a director and monitors) participated in the work. Data collection with the children was performed through a focus group, in which playful and symbolic resources were used. In addition, the family drawing was asked and a semi-structured individual interview was performed. With the professionals, semi-structured interviews were used. The results were analyzed through content analysis, and the findings showed that children have the representation of family related to their family of origin, to the single parent family and to the nuclear family. The professionals' perception is formed by the representations of their families of origin and by their perceptions of families of institutionalized children under the bias of risk and blame. Thus, it becomes necessary to open spaces for reflection on the family model with the team of the institution, so that they can notice the new family configurations in today's society and the protective factors present in the families of these children, overcoming a pathological vision.

Keywords: Family. Child institutionalized. Risk factors. Family structure. Shelters.

Resumen: Este estudio objetivó conocer la concepción de familia para niños en situación de acogimiento institucional así como para profesionales de la misma institución. Participaron del estudio tres niñas, entre nueve diez años de edad, y tres profesionales (una asistente social, una monitora y la directora). La recolección de datos con los niños fue realizada a través de un grupo focal (GF), en que fueron utilizados recursos lúdicos y simbólicos. Además, fue pedido el dibujo de la familia y realizada una entrevista semiestructurada individual. Ya con los profesionales, se hizo el uso de entrevistas semiestructuradas. Los resultados fueron analizados a través del análisis de contenido, y los datos encontrados apuntaron que los niños poseen la representación de familia relacionada a la familia de origen, a la familia monoparental y a la familia nuclear. La percepción de los profesionales está formada por las representaciones de sus familias de origen y por la percepción de las familias de los niños institucionalizados bajo el punto de vista de los riesgos y de la culpabilización. Así, se vuelve necesario abrir espacios para reflexiones sobre el modelo de familia junto al equipo de la institución, a fin de que puedan notar las nuevas configuraciones familiares en la sociedad actual y los factores de protección presentes en las familias de origen de los niños, superando una visión patologizante.

Palabras clave: Família. Niño institucionalizado. Factores de riesgo. Estrutura Familiar. Abrigos.

O presente estudo teve como objetivo conhecer a concepção de família para crianças que estão em situação de acolhimento institucional através de um grupo focal, em que foram utilizados recursos lúdicos e simbólicos. Além disso, a pesquisa buscou problematizar a concepção tradicional de família entre os profissionais de uma instituição de acolhimento. Pesquisas têm apontado que crianças abrigadas representam uma concepção de família nos moldes do modelo nuclear, bem como que, entre os profissionais que atuam diretamente com esse público, prevalecem expectativas idealizadas e estereotipadas sobre as atribuições e as posturas parentais que deveriam compor o ambiente familiar, reforçando o modelo da família nuclear burguesa (Martins \& Szymanski, 2004; Silveira, 2002; Vasconcelos, Yunes, \& Garcia, 2009). Nesse sentido, tornase importante discutir a percepção de família nas instituições de acolhimento, a fim de 
A família é considerada um sistema dinâmico e é apontada como um espaço de refúgio, que atua como um continente, delimitando atribuições, regras e lugares e desempenha

também um papel fundamental na educação do

sujeito, pois, através do processo de socialização, ocorre a perpetuação e a transmissão de valores éticos, morais, religiosos e culturais, entre outros (De Antoni \& Koller, 2000; Levy

\& Jonathan, 2010; Pelisoli, Teodoro, \& Dell'Aglio, 2007; Ramos \& Nascimento, 2008; Siqueira \& Dell'Aglio, 2006). melhor compreender os diferentes modos de estruturação familiar possíveis de serem observados na sociedade contemporânea e, da mesma forma, nas famílias de origem das crianças abrigadas.

Para Bronfenbrenner (1996/1979), a família é o primeiro microssistema com o qual a criança em desenvolvimento interage, no qual as relações devem ser estáveis, recíprocas e com equilíbrio de poder entre os diversos papéis. A família é considerada um sistema dinâmico e é apontada como um espaço de refúgio, que atua como um continente, delimitando atribuições, regras e lugares e desempenha também um papel fundamental na educação do sujeito, pois, através do processo de socialização, ocorre a perpetuação e a transmissão de valores éticos, morais, religiosos e culturais, entre outros (De Antoni \& Koller, 2000; Levy \& Jonathan, 2010; Pelisoli, Teodoro, \& Dell'Aglio, 2007; Ramos \& Nascimento, 2008; Siqueira \& Dell'Aglio, 2006).

Constata-se que a família é, por um lado, um fenômeno da natureza humana, e, por outro, é considerada uma instituição construída socialmente (Zilles, 2002). Concebe-se a família como um sistema de relações que inclui pessoas ligadas por parentesco e/ou que se sentem pertencentes a um determinado contexto (Gomes \& Pereira, 2005), e pode sofrer modificações em sua estrutura de acordo com o contexto histórico e cultural bem como a partir de um emaranhado de emoções e de ações pessoais, familiares e culturais (Pelisoli et al., 2007).

As transformações ocorridas mundialmente no âmbito socioeconômico-cultural interferem na dinâmica e na estrutura das famílias. O aumento do número de divórcios e a nova atitude da mulher e sua função na sociedade têm contribuído significativamente para a produção de mudanças (Pratta \& Santos, 2007). Assim, os papéis, a estrutura e o funcionamento da família sofreram alterações. Em consequência, o que se tem hoje são os mais diversos tipos de relações que coexistem na sociedade. $\mathrm{O}$ alto índice de pessoas que vivem sozinhas, de casais homossexuais, de casais que não são casados oficialmente, mas que moram juntos, de famílias monoparentais, isto é, de pais singulares, de netos criados pelos avós e de famílias originários do recasamento são exemplos das novas configurações familiares existentes na atualidade (Gomes \& Pereira, 2005; Martins \& Szymanski, 2004; Ramos \& Nascimento, 2008; Grzybowski, 2002).

A família é considerada a fonte principal de cuidados e de proteção às crianças, contudo, devido aos mais diversos motivos, algumas famílias apresentam dificuldade em desempenhar seu papel de cuidadora, de fornecedora de apoio e de proteção aos filhos. Esses fatores podem levar ao abrigamento dessas crianças e adolescentes quando há ameaça ou violação dos seus direitos previstos pelo ECA (Brasil, Lei no 8.069, de 13 de julho de 1990). Entre os principais riscos no contexto familiar para o desenvolvimento de uma criança, estão: presença de violência doméstica, uso de drogas por parte dos pais e negligência e práticas parentais inadequadas. A presença desses riscos pode estar associada à violência contra a criança e o adolescente, que é um dos principais motivos responsáveis pela situação de acolhimento, pois as categorias de violência física, psicológica, sexual, negligência e abandono são tipicamente prevalentes no contexto doméstico (Borges, 2007; Habigzang \& Koller, 2012).

Siqueira, Abaid e Dell'Aglio (2012) observam que, ainda na atualidade, muitos profissionais que atuam em instituições de acolhimento possuem uma visão crítica a respeito das famílias das crianças e dos adolescentes. Além de se dirigirem a essas famílias como "pedaços de famílias", ressaltam que estas 
não possuem condições de educar e de criar os filhos. Tal representação influencia no processo de reinserção familiar dessas crianças e adolescentes e perpetua a ideia de que a instituição de acolhimento é o melhor ambiente de proteção para eles. Contudo, essas representações sociais afetam a dimensão política, que baseia suas ações no assistencialismo. O Estado deveria dirigir um olhar minucioso para tais questões, pois não se trata apenas de crianças e de adolescentes abandonados ou violentados pelos pais, mas de famílias e de populações abandonadas pelas políticas e pela sociedade (Pereira, 2006).

De acordo com o Estatuto da Criança e do Adolescente (Brasil, 1990), é obrigação da família, da sociedade e do Estado assegurar à criança e ao adolescente o direito à vida, à saúde, à alimentação, à educação, ao lazer, à profissionalização, à cultura, à dignidade, ao respeito e à liberdade. Além disso, toda criança ou adolescente tem o direito de habitar junto a sua família, ou à família substituta, assegurando assim a convivência familiar e comunitária. No entanto, quando a família falha na função de proteger os filhos, o ECA (Brasil, 1990) prevê o acolhimento. Assim sendo, as crianças e os adolescentes que possuem seus direitos ameaçados ou violados são encaminhados às instituições de acolhimento como alternativa para fazer cessar o processo de risco no qual estavam envolvidos. Nesses casos, o Ordenamento Jurídico Brasileiro prioriza o interesse da criança, a fim de proteger e de decidir o que é melhor para ela. Ressalta-se que a institucionalização deveria ser temporária e cumprir os princípios estabelecidos em lei, como: manter os vínculos da criança com sua família, estimular sua participação em atividades proporcionadas pela comunidade local, não desmembrar os grupos de irmãos e atender as crianças em pequenos grupos e prepará-las para o retorno a suas famílias (Cassol \& De Antoni, 2006; Silveira, 2002;
Siqueira, Tubino, Schwarz, \& Dell'aglio, 2009; Vasconcelos et al., 2009).

O acolhimento institucional vem sendo atravessado por um intenso processo de mudanças em nosso país (Rossetti-Ferreira, Serrano, \& Almeida, 2011). Ao longo da História, as instituições de acolhimento foram conhecidas pela sociedade como a roda dos expostos, que incluíam orfanatos, internatos, abrigos e, a partir de 2009, através da Lei no 12.010 (Brasil, 2009), as instituições de acolhimento (Rossetti-Ferreira et al., 2011; Siqueira \& Dell'Aglio, 2006). Dessa forma, as crianças atendidas por essas instituições também deixaram de ser vistas como menores abandonados e passaram a ser vistas como crianças em situação de acolhimento institucional. Busca-se, com tais mudanças sociais, jurídicas e institucionais, problematizar, no cenário nacional, as novas percepções do papel das instituições de acolhimento na garantia de direitos às crianças e aos adolescentes.

Atualmente, encontra-se em vigor diretrizes de atendimento às instituições que realizam o acolhimento, a fim de garantir o direito à convivência familiar e comunitária (RossettiFerreira et al., 2011). De acordo com as normas técnicas do Conselho Nacional dos Direitos da Criança e do Adolescente - CONANDA (2008), as instituições de acolhimento devem trabalhar no sentido de garantir o convívio da criança e do adolescente com a sua família de origem bem como de garantir que o acolhimento seja uma medida protetiva excepcional e de curta duração, com o tempo máximo previsto de dois anos. Tais instituições devem ofertar atendimento individualizado para cada caso, com número reduzido de crianças e de adolescentes acolhidos, com os quais a equipe técnica busca trabalhar em prol da reinserção familiar. Por fim, as diretrizes também indicam a necessidade da preservação dos vínculos comunitários, 
ofertando espaços de cultura e lazer junto à comunidade local. Nesse sentido, o serviço de acolhimento, em parceria com a rede local e a comunidade, deverá proporcionar espaços de convivência para a criança e o adolescente no contexto social, cultural e geográfico de maior proximidade com o seu contexto de origem (CONANDA, 2008).

A instituição de acolhimento torna-se, então, para muitas crianças e adolescentes, um importante contexto ecológico de desenvolvimento, constituindo-se no microssistema desenvolvimental (Siqueira \& Dell'Aglio, 2006), que é atravessado pelas concepções de infância e de família presentes no macrossistema. Dessa forma, esta pesquisa buscou compreender a concepção de família por parte de crianças em situação de acolhimento institucional bem como dos profissionais da equipe dessa instituição e avaliar como a equipe de profissionais compreende o papel da instituição no processo de reinserção familiar.

\section{Método}

\section{Delineamento}

A pesquisa foi realizada em dezembro de 2011, em uma instituição de acolhimento para crianças e adolescentes de um Município da região noroeste do Estado do Rio Grande do Sul. De cunho qualitativo e exploratório, a pesquisa foi realizada a partir do delineamento do grupo focal (Barbour, 2009). Associado a esse modelo, buscou-se igualmente reproduzir o método de Martins e Szymanski (2004), que afirma que a brincadeira é uma forma de promover interação social, que é fundamental para a formação das crianças como pessoas, pois, a partir daí, são realizadas trocas variadas, que influenciam e são influenciadas pelos outros membros do grupo; foram também realizados uma entrevista semiestruturada e o desenho da família como instrumentos da pesquisa qualitativa, a fim de complementar os dados do GF junto à amostra das crianças.

\section{Participantes}

Participaram do GF três meninas, abrigadas em uma instituição de acolhimento, selecionadas a partir da proximidade entre as idades, que variou de nove a dez anos; participaram também três profissionais que atuavam na instituição: uma assistente social (E1), com curso superior completo, que atua há aproximadamente três anos na instituição, uma monitora (E2), que atua há cerca de seis meses na instituição, e a diretora (E3), que possui mestrado em Educação Inclusiva e que participa da equipe da instituição desde sua fundação, em 1995. As participantes da amostra das crianças foram incluídas por terem idades equivalentes e por já estarem alfabetizadas. Além disso, trata-se de uma amostra por conveniência, na qual a equipe técnica indicou as crianças que foram convidadas a participar do estudo de forma voluntária, sendo que destas, apenas três concordaram em participar. Buscou-se selecionar crianças que estivessem há mais de um mês em situação de acolhimento institucional e que a psicóloga local considerasse em maiores condições psicológicas para participar da pesquisa. Da mesma forma, a amostra dos profissionais foi de conveniência, sendo que assim foram convidados profissionais da equipe técnica, da diretoria e da equipe dos monitores. A fim de se promover um emparelhamento com o número de crianças, buscou-se então convidar um representante de cada equipe da instituição. A equipe técnica é constituída por uma psicóloga, que cumpre uma carga horária de 16 horas semanais, por uma assistente social, que trabalha 12 horas semanais, e por cinco atendentes que monitoram as crianças. A equipe diretiva, por sua vez, é formada por senhoras voluntárias da comunidade. 


\section{Instrumentos e procedimentos}

Inicialmente, foi realizado contato com as pessoas que dirigiam a instituição, sendo que, em uma visita realizada ao local, foram explicados os objetivos e o método da pesquisa. Com o aceite verbal da direção, foi solicitada assinatura do Termo de Autorização da instituição. Em seguida, foram realizadas cinco visitas ao local, com o objetivo de estabelecer um vínculo com as crianças anterior à coleta de dados bem como de discutir com a equipe técnica a indicação das meninas que poderiam participar do estudo. A psicóloga e a assistente social indicaram três meninas, que foram convidadas, e, com a concordância destas, foi solicitado que a direção assinasse o Termo de Consentimento Livre e Esclarecido.

Em data agendada, foram realizadas as entrevistas semiestruturadas individuais com as meninas participantes, e essas entrevistas foram gravadas e posteriormente transcritas, sendo as meninas também convidadas a realizar o desenho da família. Em outro momento, as meninas foram conduzidas para a atividade do grupo focal, que foi caracterizada como a brincadeira de casinha. Assim, foram disponibilizados às crianças fantasias e brinquedos que representavam uma casa. Buscou-se, assim, realizar, por meio da brincadeira e do lúdico, a representação de família e dos papéis de pai, mãe, filho e irmãos dentro de uma família, e procurou-se avaliar as situações positivas e as negativas que poderiam ocorrer dentro desse contexto. Foi realizada uma sessão única de GF de aproximadamente duas horas, na própria instituição, para o grupo das crianças participantes; a sessão de grupo foi gravada e, posteriormente, transcrita, e a pesquisadora realizou anotações em diário de bordo.

Em relação aos profissionais, foram convidados a participar da pesquisa de forma voluntária, tendo assinado o Termo de Consentimento
Livre e Esclarecido. As entrevistas foram realizadas individualmente, na própria instituição, gravadas e, posteriormente, transcritas, e tinham como foco investigar o conceito de família para cada profissional, as percepções sobre sua família de origem e acerca da família das meninas que estão na instituição e o papel da instituição na reinserção dessas meninas no contexto familiar.

\section{Critério de análise dos dados}

Após a realização das atividades com as crianças (entrevista semiestruturada, desenho da família e GF), os dados foram analisados qualitativamente a partir dos princípios da análise de conteúdo proposta por Bardin (1977). Da mesma forma, as entrevistas com os profissionais foram igualmente analisadas por esse método.

Tanto o material das crianças quanto o dos profissionais foi reunido, e, em seguida, foi realizada uma categorização dos dados. Foi adotado o critério semântico para a identificação de categorias temáticas, baseadas nos núcleos de sentido. Na produção dos resultados das meninas, foi criada a categoria percepção de família entre as crianças. Por outro lado, as categorias criadas a partir das verbalizações dos profissionais foram: percepção de família entre os profissionais e o papel da instituição de acolhimento no processo de reinserção familiar.

\section{Questões éticas}

Os procedimentos utilizados para a realização deste estudo foram embasados pela Resolução no 196/1996, do Conselho Nacional de Saúde (Brasil, 1996). Esse projeto foi submetido à avaliação de um Comitê de Ética da UNIJUí, que foi aprovado. Além disso, foi solicitada assinatura do Termo de Concordância da instituição, no qual a direção declarava concordar com a realização da pesquisa bem 
como autorizar a participação das crianças acolhidas, como sua tutora legal.

\section{Resultados e discussão}

Nesta secção, serão apresentados os resultados referentes aos dados oriundos do GF, dos desenhos e das entrevistas com as crianças bem como das entrevistas realizadas com os profissionais. Inicialmente, serão descritos os resultados obtidos junto às crianças, e após, os dos profissionais. A descrição dos casos das crianças, que compuseram o GF, será apresentada a seguir, utilizando-se nomes fictícios a fim de preservar a identidade das mesmas: Ágata, Ametista e Pérola.

\section{Caso 1}

Ágata tem nove anos e estuda no segundo ano do ensino fundamental em uma escola pública; tem três irmãos mais novos que também estavam na instituição no momento da coleta de dados. Segundo as profissionais que atuam nessa instituição, o motivo do acolhimento institucional se deve à negligência materna, uma vez que Ágata e seus irmãos permaneciam muitas horas sem a figura de um cuidador no contexto doméstico.

\section{Caso 2}

Ametista tem nove anos, cursa o segundo ano do ensino fundamental de uma escola pública e está no abrigo há cerca de quatro anos. Segundo a instituição de acolhimento, sua família biológica (mãe, avó e tio) reside em outro Município da região e tem um histórico de doença mental; associada a essa questão, havia negligência familiar em relação aos cuidados básicos de higiene. Ametista passou por duas tentativas de adoção, mas ambas não tiveram um acompanhamento adequado, o que resultou no retorno da menina ao abrigo. Em uma dessas tentativas, a menina foi para a casa de uma família adotiva com o irmão mais novo. Ametista apresenta várias alterações comportamentais, incluindo agitação psicomotora e agressividade; frente a esses comportamentos, a família adotiva decidiu ficar com o irmão, e, dessa forma, a menina retornou ao abrigo.

\section{Caso 3}

Pérola, por sua vez, tem 10 anos, cursa o quarto ano do ensino fundamental em uma escola pública, e foi entregue pela mãe para a instituição de acolhimento. Além de Pérola, a mãe abandonara dois irmãos que foram para adoção; o pai é falecido. Depois de algum tempo, a avó e uma tia da menina recorreram à Justiça para obterem sua guarda. Pérola então foi morar com a avó por um determinado tempo. No entanto, pelas dificuldades no relacionamento entre a avó, a tia e Pérola, que foi descrita como "uma menina agressiva, rebelde e que tem mau comportamento", esta foi devolvida à instituição. Após, a menina foi adotada, porém a família alegou dificuldades de relacionamento, e Pérola foi novamente devolvida à instituição de acolhimento.

\section{Percepção de família entre as crianças}

Esta categoria engloba a percepção de família proveniente dos dados da entrevista individual, dos desenhos e do GF. Os resultados em relação aos desenhos das crianças apontaram três percepções diferentes de família.

Pérola desenhou a família, formada pela avó, mãe e tia, demonstrando no seu relato que apresenta um vínculo afetivo positivo com a família de origem. Durante a entrevista e a realização do desenho, relatou que sente falta da família biológica. Quando questionada sobre "onde mora", respondeu que morava na instituição de acolhimento, mas a família biológica estava presente em suas memórias. 
Ametista, por sua vez, desenhou a si mesma e uma casa. Quando interrogada sobre "quem é a sua família", afirmou que sua família estaria dentro da casa, e que, portanto, não seria possível vê-la. Em relação à entrevista, quando questionada sobre "onde mora", respondeu que morava no Município de origem. Relata que gostaria de estar em casa, com a família de origem, com o pai e a mãe. Nesse sentido, embora não tenha desenhado os genitores, estes assumem um significado de família para ela pelos laços afetivos, que estão internalizados.

Ágata desenhou o irmão, algumas colegas da instituição de acolhimento e a si mesma. Ao referir-se ao lugar onde mora, disse que morava na instituição de acolhimento. Relatou que possui dois irmãos que moram com ela na instituição. Quando questionada sobre quem é a sua família, respondeu: A minha mãe, os meus irmãos e o pessoal daqui! Embora o motivo do acolhimento institucional seja a negligência materna, os dados da entrevista apontaram que a figura materna ainda está internalizada, bem como os irmãos, que foram desmembrados.

Dessa forma, a partir dos desenhos, podese avaliar que, nos três casos, a percepção de família dessas meninas está fortemente associada à família biológica, que, apesar da ruptura dos vínculos com esta, é emocionalmente representativa. As meninas disseram, em seus relatos, que os irmãos constituem uma importante presença na descrição de suas famílias. A concepção de família verbalizada pelas crianças corrobora a definição de Gomes e Pereira (2005), de que esta é um sistema de relações que inclui pessoas ligadas por parentesco e/ou que sentem que pertencem a um determinado contexto, ou seja, quando as meninas mencionam a própria instituição (monitores, profissionais e demais crianças) como sua família, amplia-se essa concepção para a de vínculos afetivos, que não se restringe aos laços consanguíneos. Alexandre e Vieira (2004) observam que as relações de afeto e de cuidado entre irmãos e grupos de pares nas instituições de acolhimento ostentam um significado muito específico e de grande importância para o desenvolvimento social, afetivo e cognitivo das crianças, inclusive, tais relações compõem um conjunto de fatores de proteção que promovem a resiliência.

Outro fator importante a ser considerado é que a idealização das relações familiares é muito comum em crianças que estão abrigadas em instituições de acolhimento, o que pode ser compreendido como um processo adaptativo e restaurador dos jovens destinado a resgatar as relações familiares fragilizadas (Siqueira et al., 2012). Além disso, a idealização pode estar interligada à oposição que há entre o que é de fato vivenciado, ou seja, o contexto de convivência, e o que é pensado, relacionado à maneira como a criança ou o adolescente gostaria que fosse (Siqueira et al., 2009).

As três meninas também participaram do grupo focal, em que, por meio da brincadeira de casinha e de fantasias, representaram configurações familiares. Assim, cada criança assumiu os diferentes personagens que compõem uma família. A partir dos dados, verificaram-se várias questões acerca da concepção de família dessas crianças. Para Martins e Szymanski (2004), através do brincar, a criança experimenta papéis e atitudes sociais diversos, inclusive a reprodução de práticas observadas entre os adultos, assim, podem aprender sobre a importância das relações humanas bem como sobre aspectos significativos da vida em sociedade.

Observou-se que, durante a brincadeira, dois momentos distintos de representação de uma família foram dramatizados. No primeiro momento, a família era constituída por três irmãs adultas, representadas como mães solteiras, havendo ausência da figura 
masculina. Pode-se observar que as mulheres adultas dessa família se aproximam do modelo das famílias monoparentais da atualidade. No decorrer da história, as crianças realizaram tarefas que socialmente fazem parte do universo feminino, como cuidar dos filhos e cozinhar, entre outros. Uma menina, por exemplo, pegou uma boneca e a embalou, e a outra brincou de fazer comidinha com as panelinhas.

A produção social, por meio da dinâmica das relações sociais, implica a intervenção conjunta dos dois gêneros, o masculino e o feminino, que possuem distintas distribuições de responsabilidades e modelos de comportamentos. Desse modo, associam-se a cada gênero diferentes esferas de sobrevivência, sendo mais comum na esfera doméstica o espaço próprio do gênero feminino, e a esfera pública, do gênero masculino. Socialmente, alega-se que a construção e a associação das atividades realizadas pela mulher à esfera doméstica estariam relacionadas à marca da naturalização. A partir daí, isto é, da determinação biológica, os espaços de aprendizagem e os processos de socialização reforçam estereótipos e preconceitos de gênero (Carloto, 2001).

No segundo momento, o grupo representou uma família baseada no modelo nuclear, composto por pai, mãe e filha. As meninas simulam fatos da vida cotidiana familiar em que a mãe é responsável pelas atividades domésticas e o pai coopera com a esposa. De acordo com Pratta e Santos, a família constitui um modelo ou padrão cultural que se manifesta de modos distintos nas diferentes sociedades e culturas e que, como se pode perceber, sofre transformações no transcorrer do processo histórico-social; dessa forma, é possível dizer que os diferentes tipos de composições familiares são determinados a partir de um conjunto de variáveis ambientais, sociais, econômicas, políticas, religiosas e históricas.
Observa-se que a brincadeira de Ágata, Ametista e Pérola revelou que tanto o modelo monoparental quanto o nuclear fazem parte da representação de família dessas crianças, ou seja, ambos são considerados modelos de família. Martins e Szymanski destacam que a representação de família das crianças segue o modelo conhecido e vivido no breve decorrer de suas vidas, isso dentro ou fora da instituição de acolhimento, assim como o que é veiculado por diferentes meios de comunicação. Muitas pessoas têm vivido uma variedade de arranjos familiares, como, por exemplo, famílias monoparentais, casais homossexuais, netos criados pelos avós e famílias reconstituídas, entre outros (Carvalho, 2002; Martins \& Szymanski, 2004), portanto, embora haja um ideário de família nuclear, novas configurações familiares se fazem presentes, sendo que as meninas as trouxeram em suas brincadeiras.

Além disso, verificou-se a presença de conflitos no contexto familiar no decorrer da brincadeira das crianças. Dessa forma, conflitos conjugais, traições e reconciliações, ausência da figura materna e dificuldade de os cuidadores estabelecerem limites para os filhos, características presentes em diversos lares, foram apresentados na cena familiar. No entanto, dependendo da influência do contexto, esses podem ou não constituir fatores de risco. Para Pesce, Assis, Santos e Oliveira (2004), a definição de risco não é algo estático, mas um processo, e, sendo assim, dinâmico, e deve levar em conta o somatório das mais distintas variáveis. Sabe-se que todo indivíduo está propenso a ter experiências negativas ao longo de sua história de vida. Assim, a situação de violência ou de outro tipo de evento estressor não pode ser percebida necessariamente como a causa de prejuízos na vida de crianças e adolescentes, porém, deve ser analisada a maneira pela qual o sujeito lida com o evento bem como a presença ou não de fatores de proteção que podem facilitar no processo 
de percepção e de enfrentamento do risco. Embora as crianças que participaram da pesquisa percebam que o contexto familiar pode ser caracterizado por conflitos, os fatores de risco não estão isolados como algo patológico, mas sim, em interação com os fatores de proteção e com a rede de apoio das famílias em momentos de adversidade.

Além do conflito familiar, as crianças representaram momentos de afetividade na família, principalmente os expressados por Pérola, que fez o papel de mãe. A cena foi dramatizada quando, no decorrer da brincadeira, Pérola afirma que comprou uma manta para o esposo (Ametista), coloca-a em seu pescoço, e faz carinho em seu rosto. Dessa forma, embora haja conflitos na família dramatizada, também há afetividade, ou seja, torna-se necessário notar os aspectos saudáveis das famílias em situação de vulnerabilidade.

\section{Percepção de família entre os profissionais}

Os resultados referentes a essa categoria indicaram a presença de um discurso de culpabilização das famílias de origem das crianças atendidas, uma distância entre a família de origem (estruturada) e a das crianças atendidas (desestruturadas), da percepção de fatores de risco nas famílias das crianças e da ausência de fatores de proteção, incluindo a presença de violência, de doença mental e de prostituição materna. Por fim, nos discursos desses profissionais, também emergiu a percepção de que os pais biológicos das crianças, ao cometerem algum tipo de violência, traumatizam seus filhos.

De acordo com a E2, as famílias das crianças acolhidas da instituição não têm responsabilidade e compromisso: Eu percebo que as famílias não querem responsabilidade de criar a criança. Não querem ter responsabilidade. Essa é a diferença. Não querem ter compromisso. Por isso que não procuram. Então não é porque as crianças não têm família ou parentes... Mas eles não querem compromisso.

De acordo com os relatos das entrevistas, há diferenças entre as suas famílias de origem e as famílias das crianças da instituição. As suas famílias de origem, por exemplo, foram descritas como ideais, que impõem limites, são acolhedoras e, principalmente, provedoras: - Mas era uma família assim... muito provedora, dava pouca liberdade... mas a mãe tinha muita autoridade (E3). Até hoje minha família me ajuda em tudo. (E1)

Essa visão se contrapõe à da família das crianças da instituição, vistas como irresponsáveis, doentes mentais e sem afeto. Dessa forma, torna-se necessário realizar um trabalho com os profissionais, uma vez que só é possível atuar com as famílias das crianças quando for possível um afastamento do seu ideal de família.

Os profissionais entrevistados salientaram a presença de fatores de risco nas famílias das crianças, porém não perceberam a existência de fatores de proteção. Dessa forma, ressaltou-se a doença mental como fator desencadeante da separação da criança e sua família; também se nota que é muito presente o discurso da incapacidade que tais famílias teriam em cuidar dos filhos.

Os profissionais apontaram um moralismo quanto às escolhas sexuais dos pais das crianças em situação de acolhimento institucional. Tal aspecto é visto como um fator de risco e como consequência da institucionalização de algumas crianças. Verificou-se, assim, que os profissionais possuem dificuldades em consentir com o comportamento de tais famílias, visto que estas possuem arranjos diferenciados. Para tanto, E3 afirmou: 
- Nossa maior dificuldade aqui também é porque são famílias que são formadas mais pela sexualidade do que por ligações de afeto. Então tu tem em geral uma mãe com vários maridos, com várias relações sexuais com outras pessoas que não teve vínculo afetivo, uma ligação mais emocional, duradoura. E daí a criança é tida duma mãe, mas cada um tem um pai.

A profissional continua o discurso afirmando que algumas famílias deveriam ser afastadas das crianças, devido aos danos e traumas que esses pais causariam nos filhos, acreditandose assim que a patologia seria irreversível:

- A família da instituição, a dificuldade é que ela praticamente não existe para as crianças, ou quando existe, ela traz mais problemas pra criança do que o aconchego que uma família normal traria. (...) Então é muito difícil, assim, porque a criança, ela não tem a base de quem cuida dela, então daí toda essa doença mental que grande parte das nossas crianças tem. Freud já disse, né, que o amor de pai e mãe é uma coisa básica para a sobrevivência e a saúde mental da pessoa. Nossas crianças não têm esse amor, elas não se sentem amadas por pai e mãe, a maioria deles, né. Ao contrário, o pai e a mãe são os que destroem a criança, que maltratam, que botam uma carga psicológica pro resto da vida nessas crianças.

Siqueira et al. (2009) abordam a importância de os profissionais que atuam com crianças em situação de acolhimento reconhecerem e legitimarem os diferentes modelos de família, atravessados pelos fatores culturais e sociais. Para Vasconcelos et al., ainda na atualidade, alguns profissionais que trabalham em instituições de acolhimento possuem crenças e percepções idealizadas em relação às famílias das crianças atendidas. Sendo assim, alguns deles têm a tendência de idealizar o comportamento das famílias e de Ihes prescrever expectativas e modos de vida estigmatizados pela sociedade como ideais. Além disso, Siqueira et al. (2012) ressaltam o posicionamento crítico direcionado a essas famílias, que são consideradas incapazes ou limitadas para criar, educar e cuidar dos filhos. Em consequência, essa visão disfuncional pode influenciar o processo de reinserção familiar dos jovens abrigados, visto que essas famílias seriam vistas como disfuncionais e prejudiciais aos filhos. Contudo, é fundamental que as instituições de acolhimento procurem preservar os vínculos familiares, a fim de garantir os direitos das crianças e adolescentes estabelecidos pelo ECA bem como de levar em conta o significado dessas relações para eles.

\section{O papel da instituição de acolhimento no processo de reinserção familiar}

Essa categoria engloba as verbalizações dos participantes quanto à sua percepção sobre qual seria o papel da instituição de acolhimento no processo de reinserção familiar. De modo geral, observou-se que os profissionais não reconhecem este como algo próprio do seu trabalho, bem como que há um discurso institucional de que tal papel cabe aos serviços da rede (por exemplo, ao Centro de Referência Especializado em Assistência Social, CREAS).

Os profissionais alegaram ainda que não possuem estratégias de intervenções (trabalho) junto às famílias, porém que percebem a importância desse tipo de intervenção e acreditam que ela deva ser realizada pelas políticas públicas de Estado. Assim, E1 declarou:

- Olha... quem tem que realizar com as
famílias é mais o CREAS. Agora tá vindo
bem à tona isso. (...) Então ele (o promotor)
vai explicar como deve ser feito, quem vai
fazer, que a instituição, querendo ou não,
tem transporte. E nós fazer trabalho com as
famílias não tem lugar. Não tem estrutura
pra tudo isso. Por isso acredito que quem vá
fazer esse trabalho é o CREAS. Aí vamos ver.
Se nós precisarmos fazer, também é bom.
Precisamos conhecer melhor essas famílias.

E3 acredita na funcionalidade da parceria 
entre a instituição de acolhimento e as políticas públicas:

- A gente cuida da criança, mas se o CREAS se organizar pra cuidar da família, vai ser bom, porque essas famílias precisam de atendimento, ver o que tem. As políticas públicas que têm que cuidar disso, porque não é nós que vamos fazer isso. Nossa estrutura organizacional é uma casa pra acolher.

Para Serrano (2011), o serviço de acolhimento institucional constitui um espaço de permanência, e, assim, pode ser percebido como um contexto de desenvolvimento. Desse modo, essas instituições devem ser consideradas como mais um ambiente que integram outros que fazem parte da vida da criança ou do adolescente, podendo assim se configurar com viés educativo e terapêutico. Para Bronfenbrenner (1996), o contexto da instituição de acolhimento pode ser considerado o microssistema de crianças que fazem desse contexto o nível mais imediato de relações. As interações nesse nível influenciam a vida e o desenvolvimento das crianças a tal ponto que podem inibir ou promover a expressão de competências nas esferas cognitiva, social, afetiva e éticomoral (Vasconcelos et al., 2009), portanto, a equipe que atua nos serviços de acolhimento institucional deve estar preparada para lidar com as mais diversas demandas que surgirão, além de fazer cumprir as diretrizes estabelecidas no ECA, no seu artigo 90, incisos I e III, que afirmam que as instituições de proteção são responsáveis pelo planejamento e pela execução de programas de proteção e socieducativos destinados a crianças e adolescentes em regime de orientação e apoio sociofamiliar e de colocação familiar. De acordo com as normas técnicas do CONANDA e da Lei no 12.010, de 2009 (nova lei de adoção), as instituições de acolhimento devem focar no processo de reinserção familiar e no fortalecimento dos vínculos familiares. Políticas de preservação familiar incluem apoio às famílias na resolução dos problemas psicossociais, para os quais são planejadas ações intersetoriais e interdisciplinares (Siqueira, 2012).

As orientações técnicas relativas aos serviços de acolhimento para crianças e adolescentes (CONANDA, 2008) norteiam o trabalho social com as famílias de origem. Esse documento sugere que, no momento em que a criança/ adolescente for encaminhado à instituição de acolhimento, deve ser realizado um estudo psicossocial a fim de que seja elaborado o plano de atendimento, cujo objetivo será a reinserção familiar. O planejamento das intervenções deve abranger de forma participativa a família de origem e, sempre que possível, a criança/adolescente. Desse modo, a reinserção familiar necessita ser vista como um processo gradual, sendo, portanto, acompanhado pela equipe multiprofissional da instituição de acolhimento, com o objetivo de fortalecer as relações familiares e as redes sociais de apoio da família. Contudo, para decidir se a reinserção familiar é a medida que melhor atende os interesses da criança/ adolescente, seria conveniente levar em conta elementos como: a necessidade e o desejo da família e da criança/adolescente pelo seguimento da relação afetiva, o vínculo afetivo da criança/adolescente com a família de origem, se os encaminhamentos foram efetivos e qual tem sido a resposta da família a eles e as modificações nos comportamentos violadores de relacionamento, dentre outros. As decisões sobre o destino da criança/ adolescente devem envolver a equipe técnica do serviço de acolhimento e a Justiça da Infância e da Juventude. Em circunstâncias em que a criança/adolescente possua vínculo afetivo com a família de origem, mas a reinserção familiar não seja possível devido aos mais diversos motivos, e a adoção não recomendada, há que se pensar em estratégias que contribuam com a preservação dos vínculos familiares existentes, a fim de que seja assegurado o contato com a família de origem. Nesses casos, torna-se necessário 
investir, ainda, no fortalecimento dos vínculos comunitários, visando à construção de relações significativas com pessoas da comunidade. Após a reinserção familiar, é de extrema importância que a equipe da instituição de acolhimento acompanhe o período de adaptação entre criança/ adolescente e família.

Ao finalizar este estudo, percebe-se que há um distanciamento entre a percepção de família entre crianças e profissionais e entre a visão de família de origem dos profissionais e a das famílias das crianças. Dessa forma, a problematização do conceito de família é fundamental para um trabalho dentro de instituições de acolhimento, uma vez que pode limitar as possibilidades de uma reinserção familiar. Além disso, observou-se que a instituição de acolhimento da pesquisa ainda necessita rever seu papel e adequarse à Lei no 12.010, de 2009, e às normas técnicas do CONANDA. O psicólogo, então, é um dos profissionais que pode ajudar no processo de adequação institucional bem como na flexibilização de conceitos, papéis e lugares cristalizados. Percebe-se, então, que há um hiato entre as normativas legais e a realidade institucional. Contudo, esse deve ser um trabalho permanente dentro da instituição, ou seja, de adequação e de sensibilização às diretrizes e à concepção de crianças e adolescentes, os quais têm direitos garantidos por lei pelo fato de serem cidadãos. Deve-se trabalhar ainda com a concepção de família entre os profissionais da instituição, buscando-se maior flexibilização entre meu ideal de família e a família real, potencializando os fatores de proteção e minimizando os fatores de risco através de ações intersetoriais.

\section{Conclusão}

A partir das análises das entrevistas, do desenho da família das crianças e do grupo focal, verificou-se que o grupo investigado possui três percepções distintas em relação a quem afirmam ser sua família (família biológica, família dos irmãos biológicos institucionalizados e o abrigo), ou seja, as crianças trouxeram nos relatos e nos desenhos os membros de sua família biológica, com os quais, embora não tenham vínculos atuais, ainda são importantes na sua vida. Além disso, constatou-se que os irmãos biológicos que também estão abrigados são descritos como "minha família". A instituição de acolhimento também foi concebida como a família atual.

Almeida, Maehara e Rossetti-Ferreira (2011) ressaltam a importância do relacionamento entre irmãos, especialmente no contexto de acolhimento institucional. Observa-se que tal condição possibilita a construção de vínculos, gerando relações de cuidado e afeto. Para Alexandre e Vieira (2004), as relações entre irmãos compõem um conjunto de fatores de proteção que produzem a resiliência; as instituições de acolhimento, portanto, bem como os processos de recolocação familiar, devem procurar preservar os vínculos entre irmãos, conforme o estabelecido no ECA, no artigo 92 (Brasil, 1990).

No que se refere ao modelo de família, os resultados do GF indicaram que as crianças descreveram os modelos de família monoparental e a família nuclear. A primeira foi vista chefiada por mulheres com filhos e pela presença de aspectos do gênero feminino delimitados, e a última composta por pai, mãe e filha. Martins e Szymanski (2004) observam que a representação de família de crianças segue os moldes conhecidos e, muitas vezes, experienciados por elas. Deve-se também levar em conta a influência das mídias e dos construtos sociais no processo de internalização a respeito de como é uma família. Assim sendo, verificouse que ambas as famílias representadas estão de acordo com o modelo familiar no qual as crianças participantes da pesquisa estavam inseridas no momento anterior ao acolhimento institucional. 
Embora as crianças tenham representado cenas de conflitos, ficou evidente neste estudo a presença de uma visão também favorável do contexto familiar, uma vez que as crianças relataram lembranças positivas de suas famílias de origem. Assim, pode-se pensar na possibilidade da existência de fatores positivos e protetivos entre as famílias envolvidas. No entanto, a idealização das relações familiares pode estar relacionada ao desejo intenso de retorno ao lar, e estar, de tal modo, associado à fantasia, sendo assim considerado um processo cuja finalidade é a tentativa de resgatar as relações familiares fragilizadas no momento (Siqueira et al., 2012) ou mesmo de revelar a maneira como a criança ou o adolescente gostaria que fosse sua dinâmica familiar (Siqueira et al., 2009).

Já a percepção dos profissionais sobre família é formada pelas representações de suas famílias de origem e pela percepção das famílias das crianças institucionalizadas, e, por esse motivo, a família de origem dos profissionais entrevistados foi apontada como ideal e correta, aquela que impõe limites, acolhe e, principalmente, provê cuidados aos seus membros. A concepção acerca das famílias das crianças da instituição, por sua vez, apontou na direção de famílias omissas, irresponsáveis e doentes mentais, entre outros. Tais concepções sociais influenciam o trabalho desses profissionais, principalmente a reinserção familiar de crianças e adolescentes, uma vez que muitos profissionais se utilizam de suas crenças e percepções para direcionar sua atuação.

Ainda nos discursos dos profissionais entrevistados, observou-se um conteúdo associado à culpabilização das famílias, à visão de pais sem responsabilidades e sem compromisso, a um moralismo frente às escolhas amorosas das mães e dos pais que resulta em "um filho de cada pai", no fracasso materno, e, por fim, em uma associação direta entre violência no contexto familiar e trauma infantil. Dessa forma, o presente estudo permitiu verificar que os profissionais investigados possuem a percepção de que as famílias de origem das crianças são incapazes de cuidar de seus filhos, são disfuncionais e prejudiciais aos filhos. Esse resultado corrobora a percepção de Siqueira et al. (2012), que se referem a um posicionamento crítico e frequente para com as famílias em questão, sendo estas consideradas incapazes ou limitadas para criar, educar e cuidar dos filhos. Siqueira et al. chamam a atenção para essa visão crítica a respeito das famílias das crianças e dos adolescentes, já que se costuma dirigir a essas famílias como "pedaços de famílias", ressaltando-se que elas não possuem condições de educar e de criar os filhos.

Sendo assim, foi possível constatar que houve maior foco para os fatores de risco das famílias no relato dos profissionais em detrimento dos fatores de proteção. Por outro lado, pode-se perceber uma grande diferença entre a família relatada pelas crianças e a família apresentada pelos profissionais, porque as crianças salientaram os aspectos positivos presentes em suas famílias. É fundamental, portanto, que haja uma visão cuidadosa a respeito do público atendido em instituições de acolhimento, e não estigmatizada e carregada de conceitos morais advindos de concepções e de vivências pessoais, para que seja possível salientar outros aspectos presentes nas famílias além dos fatores de risco e só assim pensar em estratégias interventivas mais eficazes e menos agressivas.

Desse modo, frente aos resultados, cabe destacar a importância da atuação do profissional de Psicologia nas instituições de acolhimento, dada a relevância de intervenções efetivas junto às crianças, às famílias de origem e também às famílias substitutas. Assim, segundo o Conselho Federal de Psicologia (1992), compete ao psicólogo atuar junto a instituições, em 
equipe multiprofissional, no diagnóstico, planejamento, execução e avaliação de programas comunitários nos domínios da saúde, lazer, educação, trabalho e segurança. Aguiar, Carrero e Rondina (2007) especificam como atribuições do psicólogo em instituições de acolhimento a realização de avaliações tanto da criança quanto de sua família, a fim de apontar as modificações que devem ocorrer para a reinserção da criança ou do adolescente na família de origem, e a realização de intervenções a fim de manter o vínculo familiar e de dar treinamento e suporte psicológico à equipe técnica. Sua atuação deve também ultrapassar as tarefas de suprir necessidades como higiene e cuidados pessoais, na tentativa de propiciar um ambiente de apoio afetivo e acolhedor, buscando amenizar as marcas da história de vida das crianças e dos adolescentes atendidos.

Este estudo apresenta algumas limitações, principalmente, por se constituir em um estudo com amostras pequenas e por conveniência. Dessa forma, não se buscam aqui generalizações dos resultados encontrados, mas uma aproximação com a realidade social. Pesquisas futuras podem incluir maior número de participantes em suas amostras bem como incluir participantes masculinos, uma vez que na atual pesquisa há um recorte de gênero - o feminino.

\section{Gianni Vanessa Mayer Lauz}

Graduada em Psicologia pela Sociedade Educacional Três de Maio (SETREM), Três de Maio - RS - Brasil. E-mail: giannimayer@hotmail.com

Jeane Lessinger Borges

Mestre em Psicologia pela Universidade Federal do Rio Grande do Sul e docente da Sociedade Educacional Três de Maio (SETREM), Três de Maio - RS - Brasil.

E-mail: jeanepsico@yahoo.com.br

Endereço para envio de correspondência:

Rua Sergipe, 234. CEP: 989000 - 000. Santa Rosa, RS.

Recebido 05/07/2012, 1a Reformulação 24/01/2013, Aprovado 11/04/2013. 


\section{Referências}

Aguiar, O. X., Carrero, M. L. C., \& Rondina, R. C. (2007). Casa abrigo: possibilidade de atuação para o psicólogo. Revista Científica Eletrônica de Psicologia, 9(5), 1-7. Recuperado em 10 março, 2012, de http://www.revista.inf.br/psicologia09/ pages/artigos/edic09-anov-art01.pdf

Alexandre, D. T., \& Vieira, M. L. (2004). Relações de apego entre crianças institucionalizadas que vivem em situação de abrigo. Psicologia em Estudo, 9(2), 207-217. doi: http://dx.doi. org/10.1590/S1413-73722004000200007

Almeida, I. G., Maehara, N. P., \& Rossetti-Ferreira, M. C. (2011). A perspectiva da criança em acolhimento institucional sobre sua rede social: a importância do relacionamento entre irmãos. In M. C. Rosseti-Clotilde, S. A. Serrano \& I. G. Almeida (Orgs.), $O$ acolhimento institucional na perspectiva da criança (pp. 119-172). São Paulo: Hucitec.

Barbour, R. (2009). Grupos focais. Porto Alegre: Artmed.

Bardin, L. (1977). A análise de conteúdo. São Paulo: Martins Fontes.

Borges, J. L. (2007). Abuso sexual infantil: consequências cognitivas e emocionais. (Dissertação de Mestrado). Programa de PósGraduação em Psicologia. Universidade Federal do Rio Grande do Sul. Porto Alegre.

Brasil. (1990). Estatuto da Criança e do Adolescente (Lei no 8.069, de 13 de agosto de 1990). Brasília, DF: Presidência da República.

Brasil. (1996). Diretrizes e normas regulamentadoras de pesquisas envolvendo os seres humanos. Conselho Nacional de Saúde, Resolução no 196, de 10 de outubro de 1996. Brasília, DF: Ministério da Saúde.

Bronfenbrenner, U. (1996). A ecologia do desenvolvimento humano: experimentos naturais e planejados. Porto Alegre: Artes Médicas (Trabalho original publicado em 1979).

Carloto, C. M. (2001). O conceito de gênero e sua importância para análise das relações sociais. Revista de Serviço Social, 10(2), 201-213.

Carvalho, M. C. (2002). A família contemporânea em debate. São Paulo: EDUC.

Cassol, L., \& De Antoni, C. (2006). Família e abrigo como rede de apoio social. In D. Dell'Aglio, S. H. Koller \& M. A. Yunes (Orgs.), Psicologia positiva: interfaces do risco à proteção (pp. 173-201). São Paulo: Casa do Psicólogo.

Conselho Nacional dos Direitos da Criança e do Adolescente \& Conselho Nacional de Assistência Social. (2008). Orientações técnicas para os serviços de acolhimento para crianças e adolescentes. Brasília, DF: CONANDA.

Conselho Federal de Psicologia. (1992). Atribuições profissionais do psicólogo no Brasil. Recuperado em 10 março, 2012, de http://www.pol.org.br/legislacao/pdf/atr_prof_psicologo.pdf

De Antoni, C., \& Koller, S. H. (2000). A visão de família entre as adolescentes que sofreram violência intrafamiliar. Estudos de Psicologia, 5(2), 347-381. doi: http://dx.doi.org/10.1590/ S1413-294X2000000200004

Gomes, M. A., \& Pereira, M. L. D. (2005). Família em situação de vulnerabilidade social: uma questão de políticas públicas. Ciência e Saúde Coletiva, 10(2), 357-369. doi: http://dx.doi. org/10.1590/S1413-81232005000200013

Grzybowski, L. (2002). Famílias monoparentais: mulheres divorciadas chefes de família. In A. Wagner (Org.), Família em cena (pp. 39-53). Petrópolis, RJ: Vozes.

Habigzang, L. F., \& Koller, S. H. (2012). Violência contra crianças e adolescentes: teoria, pesquisa e prática. Porto Alegre: Artmed.

Levy, L., \& Jonathan, E. G. (2010). Minha família é legal? A família no imaginário infantil. Estudos de Psicologia, 27(1), 49-56. http:// dx.doi.org/10.1590/S0103-166X2010000100006

Martins, E., \& Szymanski, H. (2004). Brincando de casinha: significado de família para crianças institucionalizadas. Estudos de Psicologia, 9(1), 177-187. doi: http://dx.doi.org/10.1590/ S1413-294X2004000100019

Pelisoli, C., Teodoro, M. L. M., \& Dell'aglio, D. D. (2007). A percepção de família em vítimas de abuso sexual intrafamiliar: estudo de caso. Arquivos Brasileiros de Psicologia, 59(2), 256269.

Pereira, E. V. (2006). A voz da criança institucionalizada: representações sociais de família e abrigo. (Tese de Doutorado). Universidade Estadual Paulista - UNESP, Franca, SP.

Pesce, R. P., Assis, S. G., Santos, N., \& Oliveira, R. V. C. (2004). Risco e proteção: em busca de um equilíbrio promotor de resiliência. Psicologia: Teoria e Pesquisa, 20(2), 135-246. doi: http://dx.doi. org/10.1590/S0102-37722004000200006

Pratta, E. M. M., \& Santos, M. A. (2007). Família e adolescência: a influência do contexto familiar no desenvolvimento psicológico de seus membros. Psicologia em Estudo, 12(2), 247-256. doi: http://dx.doi.org/10.1590/S1413-73722007000200005

Ramos, D. M., \& Nascimento, V. G. (2008). A família como instituição moderna. Fractal, Revista de Psicologia, 20(2), 451-472. doi: http://dx.doi.org/10.1590/S1984-02922008000200012

Rossetti-Ferreira M. C, Serrano, S. A., \& Almeida, I. G. (2011), Desafios e perspectivas para o acolhimento institucional. In M. C. Rosseti-Clotilde, S. A. Serrano \& I. G. Almeida (Orgs.), $O$ acolhimento institucional na perspectiva da criança (pp. 362403). São Paulo: Hucitec.

Serrano, S. A. (2011). Quem são as crianças institucionalizadas e suas famílias? Refletindo sobre os indicadores de abrigamento em Ribeirão Preto. In M. C. Rosseti-Clotilde, S. A. Serrano \& I. G. Almeida (Orgs.), O acolhimento institucional na perspectiva da criança (pp. 86-118). São Paulo: Hucitec.

Silveira, S. C. (2002). Família é para todos? In A. Wagner (Org.), Família em cena (pp. 54-74). Petrópolis, RJ: Vozes.

Siqueira, A. C. (2012). Avanços na legislação de proteção à criança e ao adolescente: superando desafios e construindo novas perspectivas no atendimento ao jovem em situação de institucionalização. In D. M. Arpini \& A. C. Siqueira (Orgs.), Psicologia, famílias e leis: desafios à realidade brasileira (pp. 19-70). Santa Maria, RS: UFSM.

Siqueira, A. C., \& Dell'aglio, D. D. (2006). O impacto da institucionalização na infância e na adolescência: uma revisão de literatura. Psicologia \& Sociedade, 18(1), 71-80. doi: http:// dx.doi.org/10.1590/S0102-71822006000100010

Siqueira, A. C., Abaid, J. L. W., \& Dell'aglio, D. D. (2012). Famílias e instituições de acolhimento - interfaces entre risco e proteção. In L. F. Habigzang \& S. H. Koller (Orgs.), Violência contra crianças e adolescentes: teoria, pesquisa e prática (pp. 176-189). Porto Alegre RS: Artmed.

Siqueira, A. C., Tubino, C. L., Schwarz, C., \& Dell'aglio, D. D. (2009). Percepção das figuras parentais na rede de apoio de crianças e adolescentes institucionalizados. Arquivos Brasileiros de Psicologia, 61(1), 176-190.

Vasconcelos, Q. A., Yunes, M. A. M., \& Garcia N. M. (2009). Um estudo ecológico sobre as interações da família com o abrigo. Paidéia, 19(43), 221-229. doi: http://dx.doi.org/10.1590/S0103$863 \times 2009000200010$

Zilles, U. (2002). Apresentação. In A. Wagner (Org.), Família em cena (pp. 9-11). Petrópolis, RJ: Vozes. 